\title{
$\mathrm{J}$

\section{Insight into Magnetite's Redox Catalysis from Observing Surface Morphology during Oxidation}

\author{
Shu Nie, ${ }^{\dagger}$ Elena Starodub, ${ }^{\dagger}{ }^{\S}$ Matteo Monti, ${ }^{\ddagger}$ David A. Siegel, ${ }^{\dagger}$ Lucía Vergara, $^{\ddagger}$ Farid El Gabaly, ${ }^{\dagger}$ \\ Norman C. Bartelt, ${ }^{\dagger}$ Juan de la Figuera, ${ }^{\dagger}$ and Kevin F. McCarty ${ }^{*} \dagger$ \\ ${ }^{\dagger}$ Sandia National Laboratories, Livermore, California 94550, United States \\ †Instituto de Química-Física “Rocasolano”, CSIC, Madrid 28006, Spain \\ Supporting Information
}

\begin{abstract}
We study how the (100) surface of magnetite undergoes oxidation by monitoring its morphology during exposure to oxygen at $\sim 650{ }^{\circ} \mathrm{C}$. Low-energy electron microscopy reveals that magnetite's surface steps advance continuously. This growth of $\mathrm{Fe}_{3} \mathrm{O}_{4}$ crystal occurs by the formation of bulk $\mathrm{Fe}$ vacancies. Using Raman spectroscopy, we identify the sinks for these vacancies, inclusions of $\alpha-\mathrm{Fe}_{2} \mathrm{O}_{3}$ (hematite). Since the surface remains magnetite during oxidation, it continues to

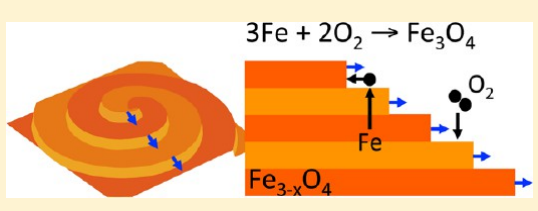
dissociate oxygen readily. At steady state, over one-quarter of impinging oxygen molecules undergo dissociative adsorption and eventual incorporation into magnetite. From the independence of growth rate on local step density, we deduce that the first step of oxidation, dissociative oxygen adsorption, occurs uniformly over magnetite's terraces, not preferentially at its surface steps. Since we directly observe new magnetite forming when it incorporates oxygen, we suggest that catalytic redox cycles on magnetite involve growing and etching crystal.
\end{abstract}

\section{INTRODUCTION}

Catalysts based on iron oxides are used in industry and are being developed for new applications because they are effective, inexpensive, and usually environmentally benign. For example, hematite $\left(\alpha-\mathrm{Fe}_{2} \mathrm{O}_{3}\right)$ is a proficient catalyst for the photoelectrolysis of water. $^{1-4}$ Iron oxide catalysts are used to manufacture hydrogen by the high-temperature water-gas shift process, where $\mathrm{H}_{2} \mathrm{O}$ and $\mathrm{CO}$ react to form $\mathrm{H}_{2}$ and $\mathrm{CO}_{2}{ }^{5,6}$ Magnetite $\left(\mathrm{Fe}_{3} \mathrm{O}_{4}\right)$ is believed to be the iron oxide phase that catalyzes the reaction. ${ }^{7,8}$ Catalysis on iron oxides has been shown to involve a cycle where the iron switches between $2+$ and $3+$ oxidation states. ${ }^{5,9}$ In the water-gas shift reaction, an $\mathrm{Fe}^{2+}$ atom in an octahedral site ${ }^{10}$ in magnetite is oxidized to $\mathrm{Fe}^{3+}$ when a $\mathrm{H}_{2} \mathrm{O}$ molecule dissociates. ${ }^{5}$ The reaction generates adsorbed oxygen and releases $\mathrm{H}_{2}$. A CO molecule reacts with the oxygen atom, forming $\mathrm{CO}_{2}$. This reaction reduces the $\mathrm{Fe}^{3+}$ to $\mathrm{Fe}^{2+}$, restoring the catalyst to its initial state. Magnetite is also reduced by exposure to pure $\mathrm{CO}$ (forming $\mathrm{CO}_{2}$ ) and oxidized by exposure to pure $\mathrm{H}_{2} \mathrm{O}$ (forming $\mathrm{H}_{2}$ ). ${ }^{11}$ The duration of these separate reactions is limited. In a mixed $\mathrm{CO} /$ $\mathrm{H}_{2} \mathrm{O}$ environment, in contrast, the separate reactions continue and their rates balance. ${ }^{11}$ The catalytic cycle of oxidizing iron by inserting oxygen into the magnetite lattice, followed by reducing the iron by removing lattice oxygen, is referred to as either a regenerative, ${ }^{11}$ a redox, ${ }^{5}$ or a Mars-van Krevelen mechanism. ${ }^{12}$

Nevertheless, questions remain unanswered about the nature of catalytic reactions on iron oxides, such as where do they occur, i.e., uniformly over the surface or only at special sites, such as atomic steps, and which crystallographic defects are created and annihilated in the regenerative cycle, vacancies, or interstitials of oxygen or iron? For metal oxide catalysts, the reactive sites are believed to be oxygen vacancies ${ }^{13-15}$ and the edges of atomic surface steps. ${ }^{15,16}$ On metals, such as ruthenium, ${ }^{17,18}$ surface steps are thought to be responsible for catalytic activity. Here we show that insight into redox reactions on magnetite can be obtained by monitoring the morphology of a particular model surface, $\mathrm{Fe}_{3} \mathrm{O}_{4}(100)$, during oxygen exposure. A simple expectation is that oxidizing magnetite leads to hematite formation: $4 \mathrm{Fe}_{3} \mathrm{O}_{4}+\mathrm{O}_{2} \rightarrow 6 \mathrm{Fe}_{2} \mathrm{O}_{3}$. Remarkably, we find that the surface steps of $\mathrm{Fe}_{3} \mathrm{O}_{4}(100)$ advance during this process, i.e., new magnetite forms at the surface during oxygen exposure. The iron needed for this growth comes from iron vacancies created in the bulk of the crystal. We propose that the vacancy creation occurs at internal boundaries where magnetite is being converted to hematite. The cation flow is balanced by an electron flow that is enabled by magnetite's high electron conductivity. The rate of volume addition to the magnetite is independent of surface step density, establishing that dissociative adsorption of oxygen occurs uniformly over the entire (100) surface, not just at step edges. Since we observe hundreds of magnetite layers being added during $\mathrm{O}_{2}$ exposure, the total amount of oxygen that can be dissociated is not limited by a fixed number of reactive surface adsorption sites. Instead, growth provides a surface that continues to be highly active for oxygen dissociation.

\section{EXPERIMENTAL SECTION}

The two natural $\mathrm{Fe}_{3} \mathrm{O}_{4}(100)$ crystals used in this study were cut and polished by MaTeck GmbH. The surfaces were prepared by $\mathrm{Ar}$ ion sputtering $\left(5 \times 10^{-6}\right.$ Torr $)$ at $1.5 \mathrm{kV}$ for $10 \mathrm{~min}$ and annealing at $\sim 600$

Received: March 13, 2013

Published: June 13, 2013 
${ }^{\circ} \mathrm{C}$ in $\sim 1 \times 10^{-6}$ Torr oxygen. Gas pressures were measured by an ionization gauge without correction. Atomic force microscopy (AFM) and Raman spectroscopy were performed in air. The latter used a backscattering geometry with a $100 \times$ objective lens, a frequencydoubled Nd:YAG laser, and a CCD detector cooled by liquid nitrogen. To understand how oxidation occurs on $\mathrm{Fe}_{3} \mathrm{O}_{4}(100)$, we monitor the motion of atomic steps using low-energy electron microscopy (LEEM) performed in an Elmitec LEEM III instrument. The step locations are determined using dark-field microscopy, as we next explain. Figure 1a

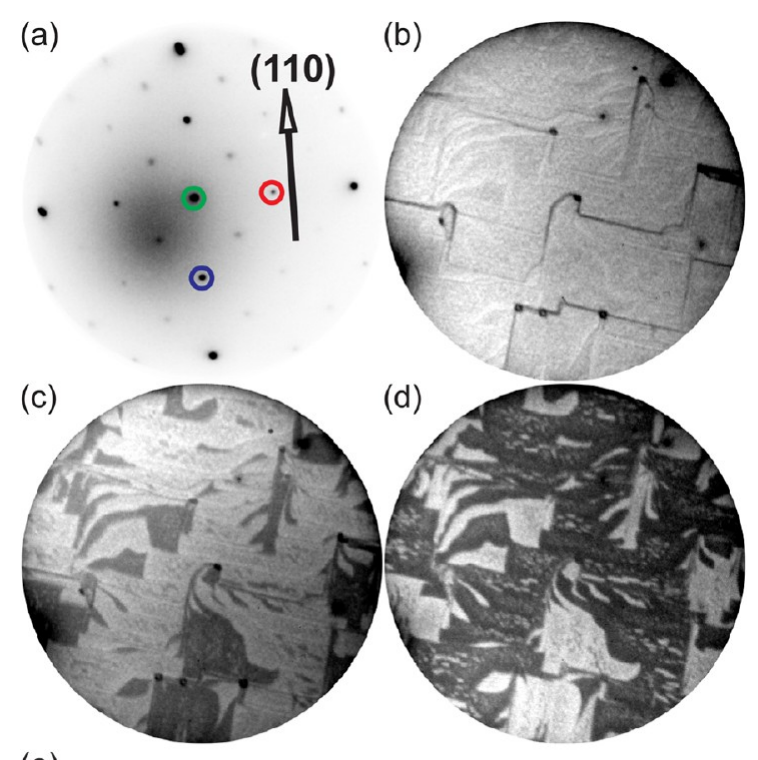

(e)

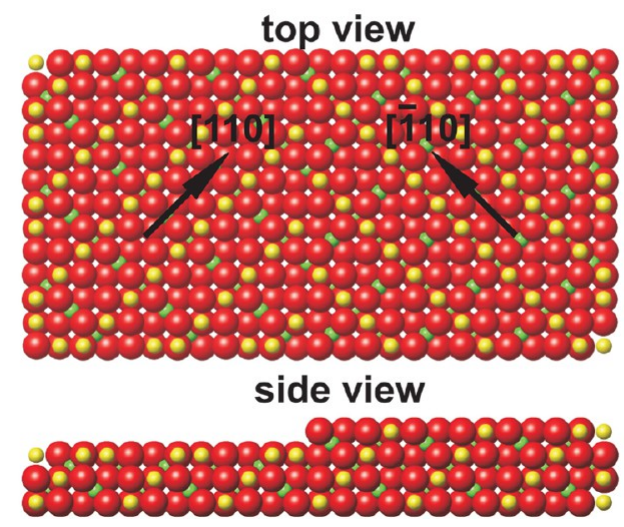

Figure 1. (a) LEED from a $20 \mu \mathrm{m}$ diameter region of the $\mathrm{Fe}_{3} \mathrm{O}_{4}(100)$ surface. The spots used to form LEEM images are circled. Electron energy $=23 \mathrm{eV}$. (b) Bright-field LEEM image from the green-circled $(0,0)$ spot. (c,d) Dark-field LEEM images from (c) the red-circled $(1,0)$ and $(\mathrm{d})$ the blue-circled $(0,1)$ spots. Electron energy $=27 \mathrm{eV}$. The LEEM images have $10 \mu \mathrm{m}$ fields of view. (e) Model showing how terraces separated by $2.1 \AA$ high steps are inequivalent. Red, yellow, and green balls are oxygen, octahedral-site iron, and tetrahedral-site iron, respectively. The rows of oxygen and iron atoms on the two adjacent terraces in the top view are perpendicular to each other. This two-fold symmetry gives dark-field contrast between terraces separated by an odd number of $2.1 \AA$ high steps, as seen in $(c, d)$.

presents a low-energy electron diffraction (LEED) pattern from $\mathrm{Fe}_{3} \mathrm{O}_{4}(100)$. Representative diffraction spots from the unit cell (5.93 $\AA$ ) of the bulk-truncated surface are circled. ${ }^{19,20}$ Between these spots are the weaker spots of the $(\sqrt{2} \times \sqrt{2}) \mathrm{R} 45^{\circ}$ surface reconstruction that is characteristic of the clean surface. ${ }^{21,22}$ A bright-field LEEM image, Figure $1 \mathrm{~b}$, is formed from the $(0,0)$ spot, circled in green. The most noticeable features, the thick dark lines, are bunches of surface steps. Figure $1 \mathrm{c}, \mathrm{d}$ is formed from the red-circled $(1,0)$ and the bluecircled $(0,1)$ spots, respectively. These two dark-field images are complementary, i.e., regions that are bright in one image are dark in the other.

The atomic model of the bulk-truncated $\mathrm{Fe}_{3} \mathrm{O}_{4}(100)$ surface shown in Figure 1e explains the origin of this dark-field contrast. The model contains a step whose height is one-quarter of the bulk unit cell (2.1 $\AA$ A). Terraces on both sides of the step are terminated with oxygen and octahedral iron, as shown by scanning tunneling microscopy (STM) images of similarly prepared surfaces. ${ }^{20,23,24}$ On the left terrace, octahedral $\mathrm{Fe}$ cations form rows along the [110] direction. On the right terrace, these rows are rotated by $90^{\circ}$, a consequence of magnetite's inverse spinel structure. ${ }^{25}$ Because a single terrace has twofold symmetry, the red and blue diffraction spots in Figure 1a from a single terrace have different intensities. Selected-area LEED from a single terrace also shows this two-fold symmetry (not shown). By choosing an electron energy where the inequivalence in diffraction intensity is large, we obtain strong bright/dark contrast between adjacent terraces, as in Figure 1c,d. We then monitor any changes to the arrangement of steps that occur during oxidation. ${ }^{26}$

\section{RESULTS}

When the $\mathrm{Fe}_{3} \mathrm{O}_{4}(100)$ crystal is heated above roughly $450{ }^{\circ} \mathrm{C}$ in oxygen $\left(>1 \times 10^{-8}\right.$ Torr $)$, we observe that the surface steps move at a constant rate. Figure 2 shows four sequential snapshots from a dark-field movie centered on a point where a dislocation with an out-of-plane component of the Burgers vector meets the surface. ${ }^{27-30}$ The images show black and white bands, corresponding to terraces separated by quarter-cell height steps, which we define as a monolayer (ML). The red dotted lines in Figure 2 mark the same step in each image. Clearly the step spiral is rotating clockwise. The motion has two alternative interpretations: One where the magnetite steps are advancing with time, which means that the crystal is growing. Or, two, where the steps are retracting and the crystal is being etched. Distinguishing between these two possibilities requires knowing the uphill and downhill directions on the surface, which LEEM alone does not easily reveal.

We resolved this ambiguity through analysis of a second crystal, which developed rectangular features that expanded with time during oxygen exposure, as observed by LEEM. AFM analysis showed that the features were flat-topped protrusions. Thus, the hot crystals are growing during oxygen exposure. (The staircase of steps in Figure 2 descends from the center of the spiral, as sketched in Figure 2e.) Examination of Movie 1, Supporting Information, reveals that the step configuration after a layer of quarter-cell height has been added is identical to the starting configuration. We observed as many as 500 layers being added in this way, which amounts to $>100 \mathrm{~nm}$ of new crystal. When the oxygen dosing was stopped, the step motion ceased and only a small amount of step smoothing was observed (see Movie 2, Supporting Information).

LEED and Raman spectroscopies (discussed below) show that the material being added to the surface is magnetite. On cooling to room temperature after oxidation, we obtain magnetite's characteristic $(\sqrt{2} \times \sqrt{ } 2) \mathrm{R} 45^{\circ}$ LEED pattern. Since $\mathrm{Fe}_{3} \mathrm{O}_{4}$ grows during oxygen exposure without an external source of iron, the iron needed to make new crystal must come from the bulk of the sample. Following the model in ref 31 for the low-temperature oxidation of magnetite to maghemite $(\gamma$ $\mathrm{Fe}_{2} \mathrm{O}_{3}$ ), we suggest that iron vacancies are created at the surface and diffuse into the bulk. This flow of vacancies provides the $\mathrm{Fe}$ needed to grow magnetite:

$$
2 \mathrm{O}_{2}+6 \mathrm{e}^{-} \rightarrow \mathrm{Fe}_{3} \mathrm{O}_{4}+3 \mathrm{~V}_{\mathrm{Fe}}^{2-}
$$



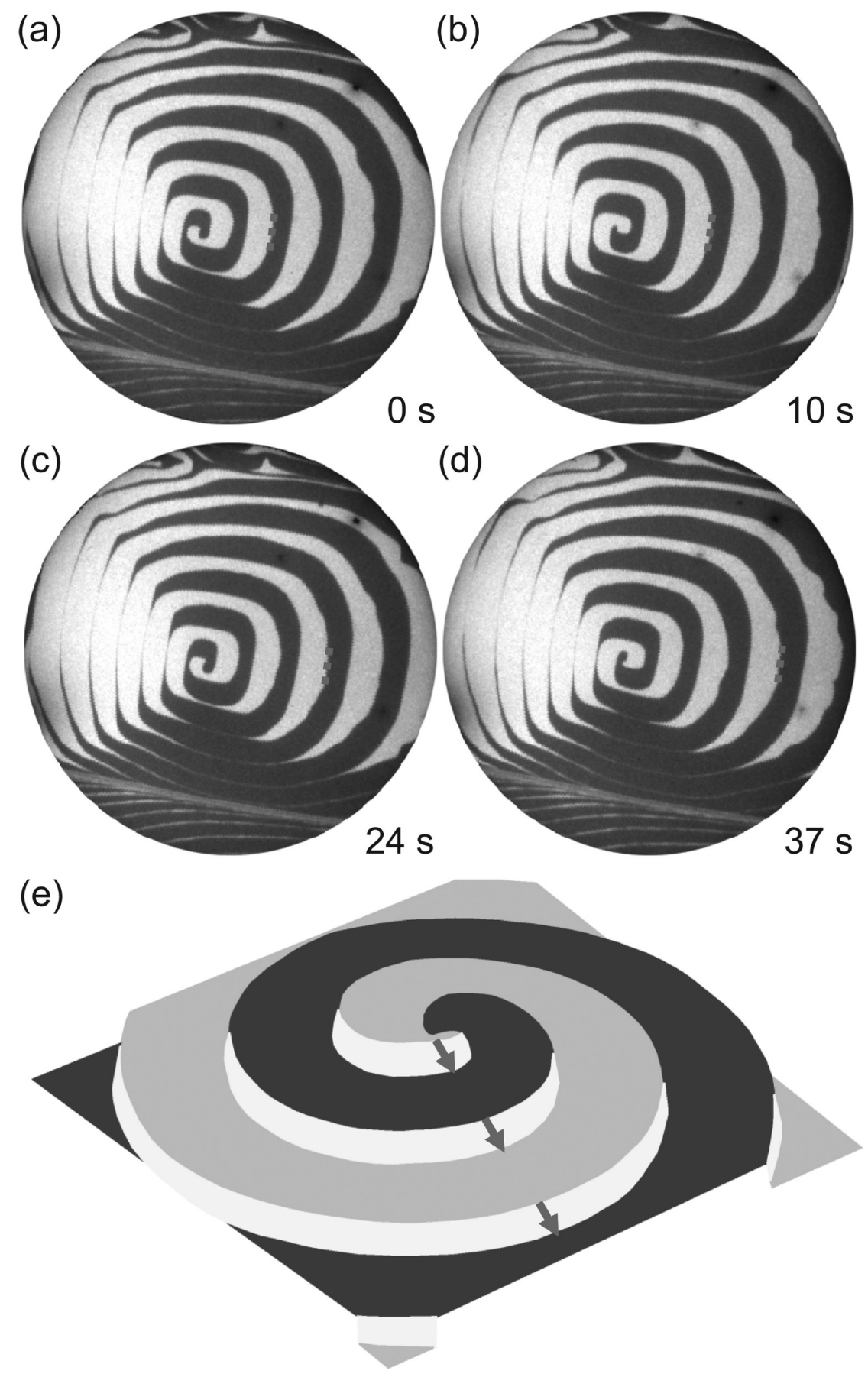

Figure 2. Sequence of dark-field LEEM images showing the growth of a $\mathrm{Fe}_{3} \mathrm{O}_{4}(100)$ surface at $650{ }^{\circ} \mathrm{C}$ during exposure to $3 \times 10^{-6}$ Torr of oxygen. Each bright/dark band is a single atomic terrace (see Figure 1). The steps that separate adjacent bands move with time, as shown by the red dotted lines that track one step. Field of view $=20 \mu \mathrm{m}$ and electron energy is $10.8 \mathrm{eV}$. (e) Schematic showing the topography around the defect (dislocation) that produces a spiral of two types of $\mathrm{Fe}_{3} \mathrm{O}_{4}(100)$ terraces separated by $2.1 \AA$ A high steps (see Figure le). Redraw from Smereka. ${ }^{44}$

where $\mathrm{V}_{\mathrm{Fe}}^{2-}$ is a (negatively) charged vacancy in magnetite. The inverse spinel structure of magnetite is known to accommodate a range of stoichiometries through vacancies on its octahedral iron sites. ${ }^{25,32}$ If there were no sinks for these vacancies, their concentration near the surface would increase until all octahedral $\mathrm{Fe}^{2+}$ sites were vacant. (This would eventually lead to the formation of maghemite, which has only $\mathrm{Fe}^{3+}$. $)^{25}$ Growth should then slow as vacancy diffusion from the vacancy-rich surface into the bulk region became rate limiting. However, we see no evidence of the parabolic growth rates characteristic of diffusion-limited growth. Nor do we see evidence for maghemite formation.

Instead we find that macroscopic domains of $\alpha-\mathrm{Fe}_{2} \mathrm{O}_{3}$ (hematite) nucleate and grow in the magnetite crystals during oxygen exposure. Indeed hematite is the equilibrium iron oxide phase at the temperatures and oxygen pressures of our experiment. $^{33}$ Figure $3 a$ shows a composite LEEM image with an L-shaped domain of different contrast. Raman spectroscopy reveals that this feature is a hematite inclusion (black spectrum in Figure $3 \mathrm{~b}$ ). Figure $\mathrm{S} 1$ shows the growth of the hematite inclusions, which were not present in the as- 

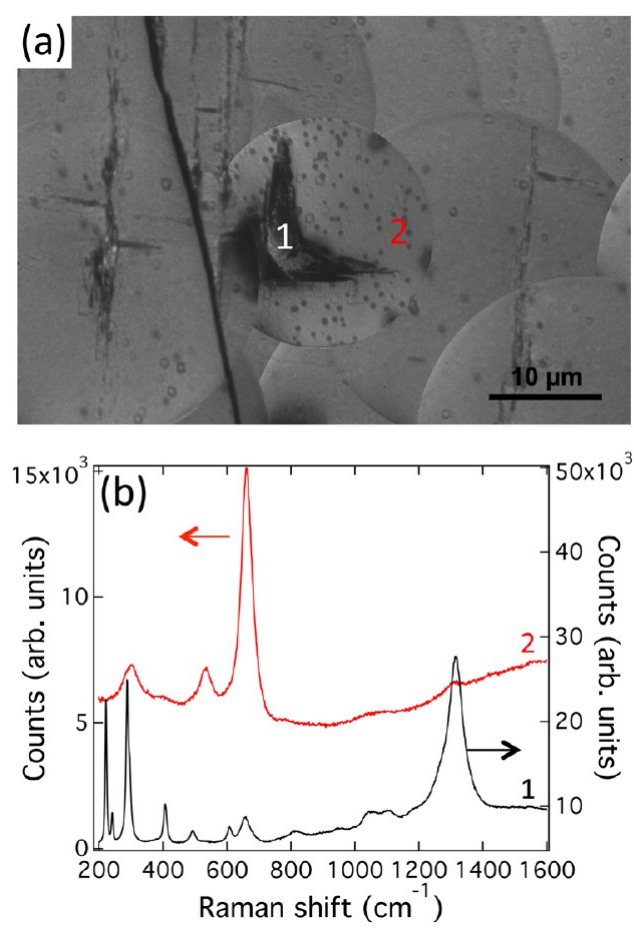

Figure 3. (a) Composite of LEEM images from a magnetite (100) crystal after cycles of sputtering and annealing in $\sim 1 \times 10^{-6}$ Torr of oxygen at $\sim 600^{\circ} \mathrm{C}$. The L-shaped region at the center is hematite. (b) Raman spectra from the two locations numbered in image (a). The Lshaped region (spectrum 1, black) is hematite based on the characteristic peaks at 222, 242, 288, 407, 493, 608, and 1316 $\mathrm{cm}^{-1}$. 5 The region around the hematite $\mathrm{L}$ shape is magnetite, as revealed by the peaks at 301,535 , and $662 \mathrm{~cm}^{-1}$. 45,46

polished crystal before high-temperature oxidation. The surrounding region is magnetite (red spectrum in Figure $3 \mathrm{~b}$ ) with the $(\sqrt{2} \times \sqrt{2})$ R45 $5^{\circ}$ LEED pattern. This characterization, along with the characteristic LEED pattern described above, establishes that the phase growing in Figure 2 is magnetite. The solid-state transformation of magnetite to hematite conserves oxygen and consumes Fe vacancies:

$$
3 \mathrm{Fe}_{3} \mathrm{O}_{4}+\mathrm{V}_{\mathrm{Fe}}{ }^{2-} \rightarrow 4 \mathrm{Fe}_{2} \mathrm{O}_{3}+2 \mathrm{e}^{-}
$$

Thus, the phase boundaries where magnetite is being converted to hematite provides the sinks for the vacancies $\left(\mathrm{V}_{\mathrm{Fe}}{ }^{2-}\right)$ created at the magnetite surface through reaction 1 . Figure 4 provides a schematic of the overall process, showing a hematite inclusion growing into the magnetite crystal along its $\langle 111\rangle$ planes. $^{34}$ Notice this mechanism requires an electron current from the hematite to the surface to counter the vacancy current. Magnetite's high electric conductivity permits the flow. ${ }^{25}$ Interestingly, the defect that acts to oxidize magnetite is iron vacancies. In contrast, oxygen vacancies in metal oxide catalysts are often assumed to be the defect where molecules adsorb and react in redox cycles. ${ }^{15}$

We next show that the initial oxidation occurs uniformly across the $\mathrm{Fe}_{3} \mathrm{O}_{4}$ surface. To do this, we measure how the local step density affects the local growth rate. (In principle, this information can also be obtained from the steady-state shape of the spirals. ${ }^{35-37}$ However, pronounced but uncharacterized crystalline anisotropies and incomplete knowledge of the full surface topology around the spiral confound this approach.) At the center of the spiral, the step velocity is zero because the Gibbs-Thomson pressure due to step curvature counteracts

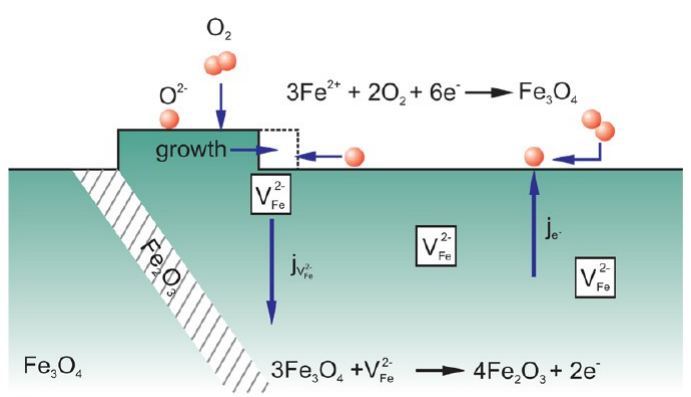

Figure 4. Schematic illustration of oxidation of the $\mathrm{Fe}_{3} \mathrm{O}_{4}(100)$ surface. Gas-phase oxygen dissociatively adsorbs uniformly over the surface (Figure 5), leading to oxygen reduction and Fe oxidation. An $\mathrm{O}$ or $\mathrm{O} / \mathrm{Fe}$ species diffuses to the atomic step edge, where new magnetite crystal grows. About one-fourth of the $\mathrm{O}_{2}$ molecules that strike the surface are incorporated into new magnetite (Figure 6). Iron for the crystal growth initially comes from creating iron vacancies in the bulk of the magnetite and eventually from the nucleation and growth of hematite, $\alpha-\mathrm{Fe}_{2} \mathrm{O}_{3}$. Conversion between magnetite and hematite provides a sink/source of iron vacancies, which provides a large reservoir of oxygen at the surface that can participate in chemistry.

the driving force for growth. To remove curvature effects we studied regions of the spiral where the curvature was much smaller than the central curvature. Figure 5a shows one frame from a growth movie. The dashed line marks a horizontal row of pixels that is centered on the spiral. All the pixel rows from the image sequence are stacked up along the $y$ axis in Figure 5b. A vertical cut though this stack shows the terrace edges (steps) that pass by a given location with time. The slope of a bright/ dark boundary gives the inverse step velocity at that location. Simple inspection reveals that the step velocity varies with position. In particular the slopes of the boundaries on the left side of Figure $5 b$ are significantly greater than the slopes on the right side.

Insight into the origin of the variable step velocity comes from examining the image in Figure 5a. Along the right side of the dashed line, adjacent terraces have roughly equal widths. On the left side, in contrast, the bright terraces are considerably wider than the dark terraces. Figure $5 b$ reveals that the righthand steps move about twice as fast as the left-hand steps. Note that the combined width of two adjacent terraces on the right is about twice the width of adjacent terraces on the left side. These observations suggest that the growth speed is proportional to terrace width. Indeed, a statistical study shows that this is the correct interpretation. Figure 5c plots the local growth speed as a function of terrace width for two oxygen pressures. Because one type of terrace on the left side of Figure $5 b$ is too narrow to measure accurately, we measure the width of two adjacent terraces. We call this distance the biterrace width, which is illustrated in Figure 5d. (The Supporting Information explains the analysis details.) The plot shows that there are indeed large differences in the local velocity-over a factor of 2 . And we find a linear dependence of growth speed on terrace width. So the velocity of a step scales with the width of its adjacent terraces.

Additional information about where oxidation occurs comes from measuring how the oxidation rate scales with oxygen pressure, as shown in Figure 6a. We measured the rate at which the steps emanating from a dislocation with screw character were swept through a given location. The inverse of the time (see Figure 2) needed to add a new one-fourth cell height layer 
(a)

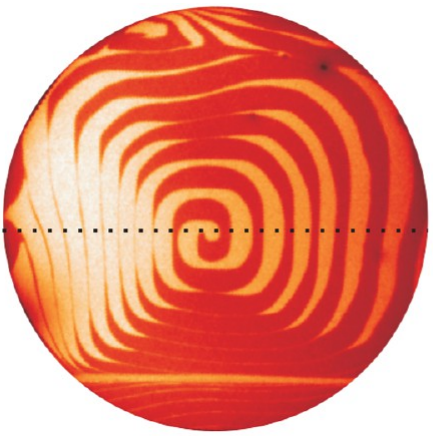

(b)

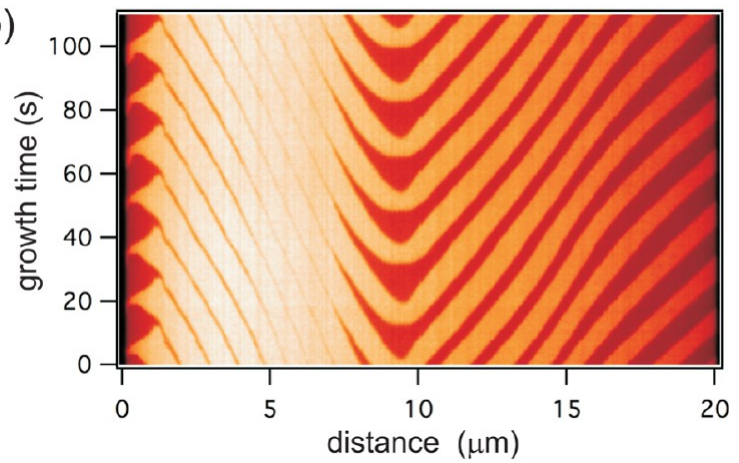

(c)
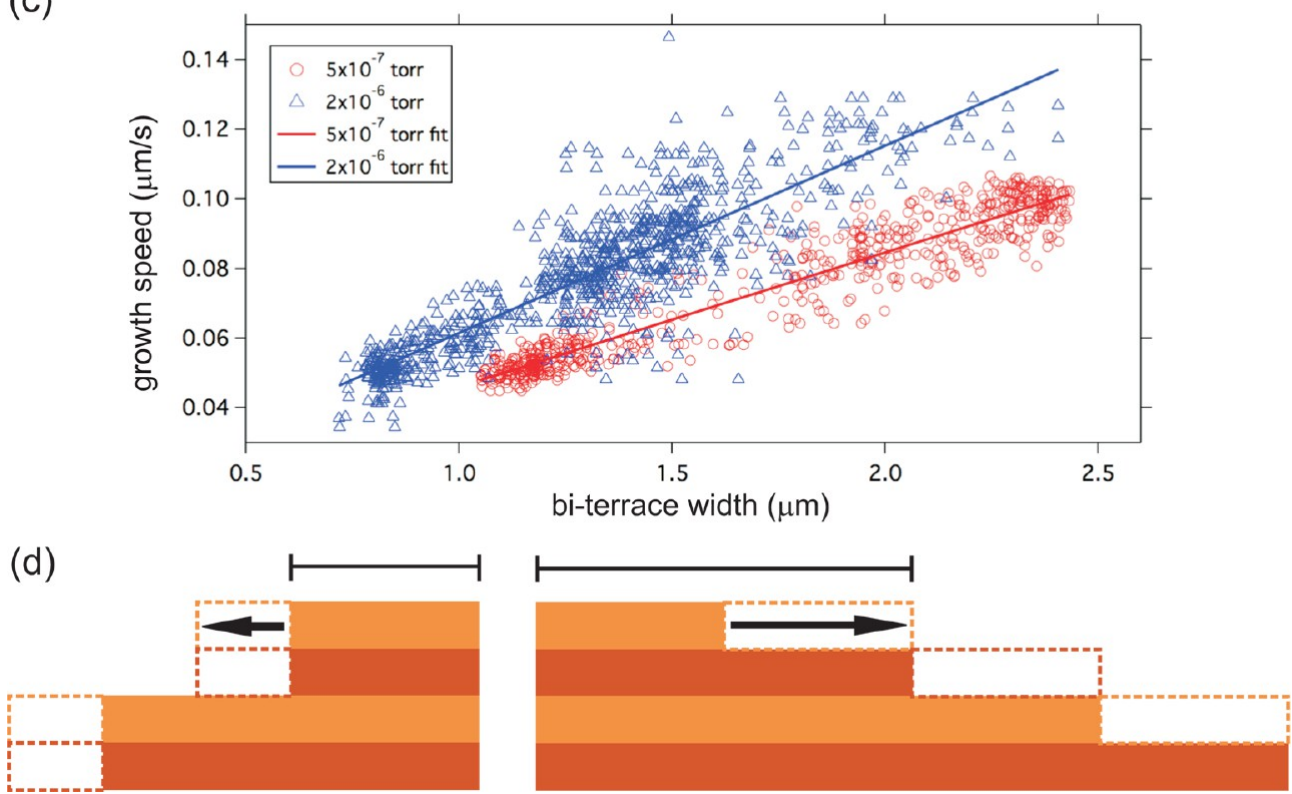

Figure 5. (a) Dark-field LEEM image taken from a movie of magnetite growing around a dislocation $\left(650{ }^{\circ} \mathrm{C}, 2 \times 10^{-6}\right.$ Torr oxygen). Each band is single $\mathrm{Fe}_{3} \mathrm{O}_{4}(100)$ terrace. Adjacent terraces are separated by a surface step. Field of view $=20 \mu \mathrm{m}$. The dashed line marks the row of pixels that are stacked to compose (b), where the slope of the bands is the inverse step velocity at a given position. Steps on the right side move about twice as fast as steps on the left side. (c) Growth speed versus terrace width at two oxygen pressures. The solid lines are fits, showing that the growth speed is proportional to the local terrace width. The slopes of the fitted blue and red lines are $0.0538 \pm 0.0007$ and $0.0387 \pm 0.0005 \mathrm{~s}$, respectively, with higher pressure giving the higher rate. (d) Schematics showing the dependence of growth speed on terrace width. Left: Bunched steps, as in the left side of image (a). Right: Equally spaced steps, as in the right side of image (a). Since the volume of crystal added scales with surface area, two bunched steps move half as fast as isolated steps. The square-ended lines define the biterrace width.
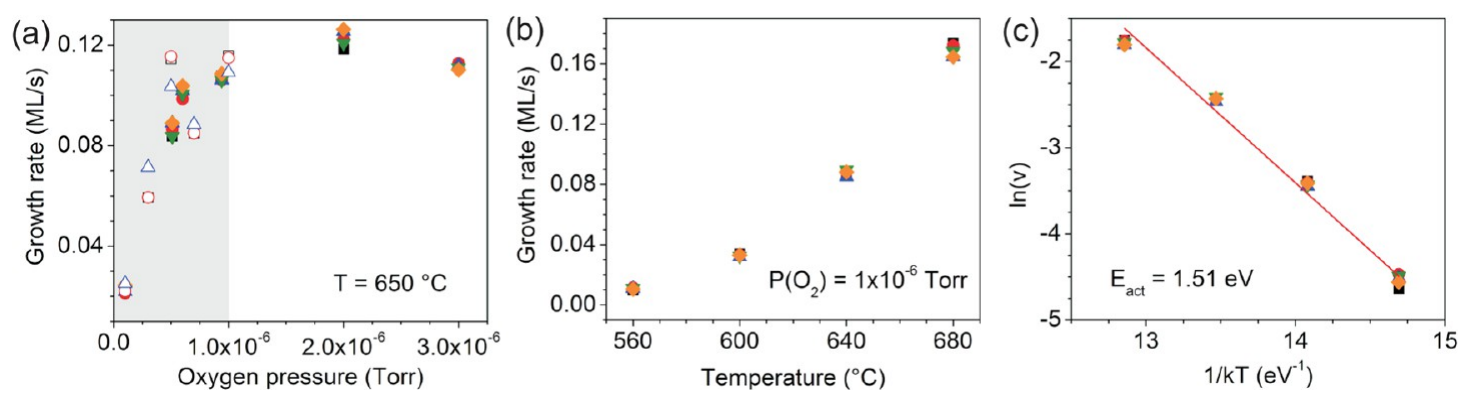

Figure 6. (a) Growth rate vs oxygen pressure at $650^{\circ} \mathrm{C}$. Open and filled markers are from two different regions on the surface. The different markers are measured at different spots in the same field of view. (b) Growth rate vs temperature in $1 \times 10^{-6}$ Torr oxygen. (c) Arrhenius plot of growth rate vs temperature. The activation energy is $1.51 \pm 0.14 \mathrm{eV}$.

(see Figure 1e) gives the growth rate (see Figure 6a). There are two regimes of growth in the plot. In the low-pressure regime shaded with gray (oxygen pressure $<1 \times 10^{-6}$ Torr), the growth rate increases linearly with oxygen pressure. In the highpressure regime (oxygen pressure $>1 \times 10^{-6}$ Torr), the growth rate saturates at $\sim 0.12 \mathrm{ML} / \mathrm{s}$. We quantify the fraction of incident oxygen molecules that become incorporated into the crystal as follows. The number of oxygen atoms added per area is the growth rate times the new layer's oxygen density, which is $4 / a^{2}$, where $a$ is magnetite's bulk lattice constant $(8.396 \AA) .{ }^{25}$ And from the classical kinetic description of gases, ${ }^{38}$ the rate at which oxygen molecules strike the surface (molecules/area/ 
time $)$ is $\bar{p} /(2 \pi m k T)^{1 / 2}$, where $k$ is the Boltzmann constant, and $\bar{p}, m$, and $T$ are the oxygen pressure in the LEEM chamber and oxygen's molecular weight and temperature (room temperature), respectively. In the linear regime of Figure 6a, we find that about $26 \%$ of the incident oxygen molecules become incorporated into oxide. This high conversion efficiency results from the entire surface being active for $\mathrm{O}_{2}$ dissociation.

\section{DISCUSSION}

We return to Figure 4 to discuss the mechanism of magnetite oxidation. Molecular oxygen is not stable on magnetite ${ }^{39}$ or hematite $^{40}$ at our temperatures and pressures. So oxygen must dissociate to adsorb on the $\mathrm{Fe}_{3} \mathrm{O}_{4}(100)$ terraces. The dissociation necessarily transfers electrons from the iron cations to the oxygen, causing $\mathrm{Fe}$ oxidation: $\mathrm{Fe}^{2+} \rightarrow \mathrm{Fe}^{3+}$. For simplicity we denote the adsorbed species as $\mathrm{O}^{2-}$ in Figure 4, although we lack detailed knowledge of its charge state. This species, or perhaps one containing both $\mathrm{O}$ and $\mathrm{Fe}$, diffuses to the edge of a magnetite step. There the species is incorporated into the crystal, leading to crystal growth. The iron for the new magnetite has to come from the bulk. The complete reduction of the adsorbed oxygen to $\mathrm{O}^{2-}$ may not occur until the oxygen is fully incorporated into the magnetite lattice. But the initial oxidation happens uniformly over the entire surface. The mechanism explains the $\sim 2$ times difference in step velocity in Figure 5, as the schematic of Figure 5d illustrates. The rate of oxygen dissociation scales with surface area, so it is independent of terrace width. And the total flux of growth species to the steps is also independent of terrace width. But the flux per step scales inversely with the step density. So the double-height steps move half as fast as the single-height steps to sink the same oxygen flux.

Magnetite oxidation occurs through two spatially separated reactions. First, the reaction of oxygen at the surface generates iron vacancies (reaction 1). Second, the conversion of magnetite to hematite at internal interfaces consumes these iron vacancies (reaction 2). The net reaction is simply that magnetite is converted to hematite, but for every 12 formula units of $\mathrm{Fe}_{2} \mathrm{O}_{3}$ created, one unit of $\mathrm{Fe}_{3} \mathrm{O}_{4}$ is added to the surface:

$$
9 \mathrm{Fe}_{3} \mathrm{O}_{4}+2 \mathrm{O}_{2} \rightarrow 12 \mathrm{Fe}_{2} \mathrm{O}_{3}+\left(\mathrm{Fe}_{3} \mathrm{O}_{4}\right)_{\text {surface }}
$$

Thus, we have the unusual situation where two different phases, both exposed to the same gas environment (Figure 4), are growing simultaneously. The iron liberated in forming hematite from magnetite does not react with the gas-phase oxygen to form more hematite. A nucleation event is needed to initiate hematite formation since magnetite and hematite have different crystal structures [inverse spinel (cubic) and corundum (hexagonal), respectively]. ${ }^{25}$ So hematite does not grow where the iron vacancies are being formed, i.e., uniformly over the surface. Instead, the liberated iron reacts at the magnetite surface to grow more magnetite epitaxially, despite the fact that either hematite or maghemite would be closer to being in equilibrium with the oxygen gas. ${ }^{33}$ If the process were reversed (hematite converting to magnetite), then oxygen would be liberated. Thus, the conversion between hematite and magnetite provides a large reservoir of oxygen. Since this oxygen is stored and released at the surface through the $\left(\mathrm{Fe}_{3} \mathrm{O}_{4}\right)_{\text {surface }}$ material in reaction 3, it is available for participating in surface chemistry. We note that the diffusion of iron vacancies is long ranged. That is, there is no hematite in the field of view of Figures 2 and 5 a yet magnetite grows without abatement. Iron is diffusing at length scales exceeding many tens of micrometers. This ability to transport reactive iron vacancies between the bulk and the surface over long length scales illustrates the rich chemistry of iron oxide systems. One expects that magnetite growth to be faster near the hematite crystals. We confirmed this expectation by examining the surface topography after oxidation.

The iron vacancy generation that accompanies hematite formation leads to a magnetite (100) surface that is remarkably active for reaction with oxygen-over one-quarter of the oxygen molecules that impinge on the surface undergo dissociative adsorption and eventual incorporation into an oxide crystal. The very high value illustrates the extreme reactivity of a magnetite surface that is chemically coupled to hematite. At sufficiently high pressure $\left(>1 \times 10^{-6}\right.$ Torr, in Figure $6 \mathrm{a}$ ), the rate of crystal growth saturates. Some insight into the regime comes from its strong dependence of growth speed on temperature, as shown in Figure 6b. An Arrhenius plot, Figure $6 \mathrm{c}$, gives an activation energy of $1.5 \mathrm{eV}$. Under these saturated (high-pressure) conditions, some process that is, for example, blocking dissociative oxygen adsorption or limiting the rates of iron vacancy generation or diffusion, has a large energetic barrier. In contrast, the extreme efficiency of $\mathrm{O}$ incorporation at low pressures suggests that no large barrier is important there. With decreasing temperature, the onset of the saturated growth regime will occur at increasingly lower pressures as the saturated velocities become much smaller than the incoming $\mathrm{O}$ flux. Presumably this effect accounts for the lack of measurable growth at temperatures beneath roughly $450{ }^{\circ} \mathrm{C}$ in $10^{-6}$ Torr of $\mathrm{O}_{2}$. This temperature is consistent with the temperature needed by Parkinson et al. to heal the damage of sputtered $\mathrm{Fe}_{3} \mathrm{O}_{4}(100)$ surfaces by surface-bulk diffusion. ${ }^{41}$

We contrast our finding of dissociative oxygen adsorption all over the surface with results from other systems. Ertl and coworkers showed that $\mathrm{NO}$ dissociates at the steps of a $\mathrm{Ru}(0001)$ surface even though the amount of $\mathrm{NO}$ dissociation scaled with the $\mathrm{Ru}$ terrace width. ${ }^{17}$ In this case, the chemical reaction occurred at the step edges. So if the step edges are made inactive, as done by Dahl et al., ${ }^{18}$ reaction (dissociation) will practically stop. In contrast, the initial reaction of $\mathrm{Fe}_{3} \mathrm{O}_{4}$ oxidation occurs uniformly on the terraces, not at the steps. This means that the redox cycle needed for catalysis can occur everywhere on the surface, independent of surface steps. Another limiting regime has been observed during oxidation of $\mathrm{TiO}_{2-x}$. Because the residence time of adsorbed oxygen was relatively small, only oxygen that adsorbed close to atomic surface steps participated in crystal growth. ${ }^{42}$ In the extreme limit, all the reactions that are trying to bring a surface into chemical equilibrium with its bulk or a gas-phase environment occur only at the surface steps. Such behavior has been observed during the equilibration of bulk thermal defects with the surface of a metallic alloy, $\mathrm{NiAl}^{43}$

\section{CONCLUSION}

We summarize and conclude by discussing the implications of our findings for surface chemistry on iron oxides. First, simply exposing $\mathrm{Fe}_{3} \mathrm{O}_{4}(100)$ to oxygen at moderate temperatures and pressures creates new magnetite layers (Figure 2). The growth occurs by creating iron vacancies at the surface (reaction 1 ). This fact alone establishes that iron vacancies in magnetite allow its oxidation/reduction. In reactions that occur by the Mars-van Krevelen mechanism, such as the water-gas shift reaction, ${ }^{11}$ oxygen is alternately inserted into and removed from 
the oxide lattice during the catalytic cycle. We directly observe that oxygen incorporation into magnetite leads to crystal growth, i.e., both $\mathrm{Fe}$ and $\mathrm{O}$ are added to the surface. Thus, we suggest that the catalytic cycle actually involves growing and etching magnetite crystal by creating and destroying iron vacancies, respectively. In contrast, catalysis on metal oxides is usually assumed to occur through the creation and destruction of oxygen vacancies, ${ }^{15}$ a cycle that does not move the metal cations.

Second, from the dependence of step velocity on local topography, we find that the oxidation of $\mathrm{Fe}_{3} \mathrm{O}_{4}(100)$ occurs uniformly over its surface (Figure 5). More specifically, the first process that removes electrons from iron cations, dissociative adsorption of oxygen, occurs uniformly on terraces. Ultimately, though, this oxygen becomes incorporated into the crystal at surface steps. We anticipate that magnetite reduction occurs simply by reversing the mechanism shown in Figure 4 . Then both iron oxidation and reduction, the two parts of a regenerative catalytic cycle, ${ }^{11}$ occur over the entire (100) surface. Having chemical reactivity distributed over the entire surface can offer faster net reaction rates than the situation where only special sites, such as surface steps, have significant activity. Finally, oxidizing magnetite to hematite forms magnetite at the (100) surface (reaction 3), which stores oxygen there. The reverse process, which we have not examined here, releases oxygen. Surface reactions can be sustained by the reservoir of surface oxygen. The transport of the reactive species through the magnetite, iron vacancies, and electrons, can occur over many micrometers of distance, long compared to the nanometer-dimension particles common in catalysis.

\section{ASSOCIATED CONTENT}

\section{S Supporting Information}

Movies of magnetite growth during oxygen exposure and lack of growth in vacuum, documentation of hematite growth during magnetite oxidation, and a detailed description of measuring the dependence of growth velocity on local topography (Figure 5c). This material is available free of charge via the Internet at http://pubs.acs.org.

\section{AUTHOR INFORMATION}

\section{Corresponding Author}

mccarty@sandia.gov

\section{Present Address}

${ }^{\S}$ KLA-Tencor, Milpitas, CA 95035

\section{Notes}

The authors declare no competing financial interest.

\section{ACKNOWLEDGMENTS}

Our research was supported by the Office of Basic Energy Sciences, Division of Materials and Engineering Sciences, U.S. Department of Energy under contract no. DE-AC0494AL85000 and the Spanish Ministry of Science and Innovation through project no. MAT2009-14578-C03-01.

\section{REFERENCES}

(1) Kay, A.; Cesar, I.; Gratzel, M. J. Am. Chem. Soc. 2006, 128, 15714.

(2) Walter, M. G.; Warren, E. L.; McKone, J. R.; Boettcher, S. W.; Mi, Q. X.; Santori, E. A.; Lewis, N. S. Chem. Rev. 2010, 110, 6446.

(3) Gamelin, D. R. Nat. Chem. 2012, 4, 965.

(4) Klahr, B.; Gimenez, S.; Fabregat-Santiago, F.; Hamann, T.; Bisquert, J. J. Am. Chem. Soc. 2012, 134, 4294.

(5) Ratnasamy, C.; Wagner, J. P. Catal. Rev.: Sci. Eng. 2009, 51, 325.
(6) Estrella, M.; Barrio, L.; Zhou, G.; Wang, X. Q.; Wang, Q.; Wen, W.; Hanson, J. C.; Frenkel, A. I.; Rodriguez, J. A. J. Phys. Chem. C 2009, 113, 14411.

(7) Rethwisch, D. G.; Dumesic, J. A. Appl. Catal. 1986, 21, 97.

(8) Bartholomew, C. H.; Farrauto, R. J. Fundamentals of Industrial Catalytic Processes, 2nd ed.; John Wiley \& Sons: Hoboken, NJ, 2006.

(9) Reddy, G. K.; Boolchand, P.; Smirniotis, P. G. J. Phys. Chem. C 2012, 116, 11019.

(10) Topsoe, H.; Boudart, M. J. Catal. 1973, 31, 346.

(11) Boreskov, G. K.; Yur'eve, T. M.; Sergeeva, A. S. Kinet. Katal. 1970, 11, 1476.

(12) Mars, P.; van Krevelen, D. W. Chem. Eng. Sci. 1954, 3 (Sup. 1), 41.

(13) Lu, G.; Linsebigler, A.; Yates, J. T. J. Phys. Chem. 1995, 99, 7626.

(14) Henderson, M. A.; Epling, W. S.; Perkins, C. L.; Peden, C. H. F.; Diebold, U. J. Phys. Chem. B 1999, 103, 5328.

(15) Campbell, C. T.; Peden, C. H. F. Science 2005, 309, 713.

(16) Hendriksen, B. L. M.; Ackermann, M. D.; van Rijn, R.; Stoltz, D.; Popa, I.; Balmes, O.; Resta, A.; Wermeille, D.; Felici, R.; Ferrer, S.; Frenken, J. W. M. Nat. Chem. 2010, 2, 730.

(17) Zambelli, T.; Wintterlin, J.; Trost, J.; Ertl, G. Science 1996, 273, 1688.

(18) Dahl, S.; Logadottir, A.; Egeberg, R. C.; Larsen, J. H.; Chorkendorff, I.; Tornqvist, E.; Norskov, J. K. Phys. Rev. Lett. 1999, $83,1814$.

(19) Tarrach, G.; Burgler, D.; Schaub, T.; Wiesendanger, R.; Guntherodt, H. J. Surf. Sci. 1993, 285, 1.

(20) Stanka, B.; Hebenstreit, W.; Diebold, U.; Chambers, S. A. Surf. Sci. 2000, 448, 49.

(21) Pentcheva, R.; Wendler, F.; Meyerheim, H. L.; Moritz, W.; Jedrecy, N.; Scheffler, M. Phys. Rev. Lett. 2005, 94, 126101.

(22) Pentcheva, R.; Moritz, W.; Rundgren, J.; Frank, S.; Schrupp, D.; Scheffler, M. Surf. Sci. 2008, 602, 1299.

(23) Fonin, M.; Pentcheva, R.; Dedkov, Y. S.; Sperlich, M.; Vyalikh, D. V.; Scheffler, M.; Rudiger, U.; Guntherodt, G. Phys. Rev. B 2005, 72, 104436.

(24) Parkinson, G. S.; Novotny, Z.; Jacobson, P.; Schmid, M.; Diebold, U. J. Am. Chem. Soc. 2011, 133, 12650.

(25) Cornell, R. M.; Schwertmann, U. The Iron Oxides: Structure, Properties, Reactions, Occurences and Uses; Wiley-VCH Verlag GmbH \& Co.: Weinheim, 2003.

(26) By comparing surface regions exposed to the electron beam for long times to regions only briefly exposed, we found no evidence that the electron beam damaged the surface under our imaging conditions. Also, magnetite growth during oxidation occurred in the absence of the electron beam.

(27) Kodambaka, S.; Khare, S. V.; Swiech, W.; Ohmori, K.; Petrov, I.; Greene, J. E. Nature 2004, 429, 49.

(28) Meng, F.; Morin, S. A.; Jin, S. J. Am. Chem. Soc. 2011, 133, 8408.

(29) Yanina, S. V.; Carter, C. B. Surf. Sci. 2002, 511, 133.

(30) Yanina, S. V.; Carter, C. B. Surf. Sci. 2002, 513, L402.

(31) Gallagher, K.; Feitknecht, W.; Mannweiler, U. Nature 1968, 217, 1118.

(32) Dieckmann, R. Ber. Bunsen-Ges. Phys. Chem. Chem. Phys. 1982, $86,112$.

(33) Ketteler, G.; Weiss, W.; Ranke, W.; Schlogl, R. Phys. Chem. Chem. Phys. 2001, 3, 1114.

(34) Feitknecht, W.; Mannweiler, U. Helv. Chim. Acta 1967, 50, 570.

(35) Burton, W. K.; Cabrera, N.; Frank, F. C. Philos. Trans. R. Soc., A 1951, A243, 299.

(36) Van der Eerden, J. P. J. Cryst. Growth 1981, 53, 305.

(37) Van der Eerden, J. P. J. Cryst. Growth 1981, 53, 315.

(38) Reif, F. Fundamentals of Statistical and Thermal Physics; McGraw-Hill, Inc.: New York, 1965; p 273.

(39) Udovic, T. J.; Dumesic, J. A. J. Catal. 1984, 89, 314.

(40) Yang, B. L.; Kung, H. H. J. Catal. 1982, 75, 329.

(41) Parkinson, G. S.; Novotny, Z.; Jacobson, P.; Schmid, M.; Diebold, U. Surf. Sci. 2011, 605, L42.

(42) McCarty, K. F.; Bartelt, N. C. J. Cryst. Growth 2004, 270, 691. 
(43) McCarty, K. F.; Nobel, J. A.; Bartelt, N. C. Nature 2001, 412, 622.

(44) Smereka, P. Phys. D (Amsterdam, Neth.) 2000, 138, 282.

(45) McCarty, K. F.; Boehme, D. R. J. Solid State Chem. 1989, 79, 19.

(46) de Faria, D. L. A.; Silva, S. V.; de Oliveira, M. T. J. Raman Spectrosc. 1997, 28, 873. 